\title{
A Study on the Professional Standards of Pre-service Teachers in Middle and Western Primary Schools in the Horizon of Competency
}

\begin{abstract}
Guang Li
Baoshan College, Baoshan, Yunnan 678000

*Corresponding author. Email: 781216468@qq.com

ABSTRACT

The research on the professional standards of pre-service teachers in elementary schools is helpful to provide references for the improvement of talent training programs in colleges and universities, and to provide specific guidance for the self-development and self-improvement of pre-service teachers. Taking the western elementary pre-service teachers as the research object, using questionnaires, interviews and mathematical modeling methods to construct the competency structure of western elementary pre-service teachers including knowledge and skills, teamwork, achievement orientation, initiative, sense of responsibility, and training Others and interpersonal understanding factors have a good degree of fit after testing. The competency structure of pre-service teachers in western elementary schools is highly consistent with the professional standards of primary school teachers. The research on the professional standards of pre-service teachers in western elementary schools includes professional concepts and teacher ethics, professional knowledge and professional abilities.
\end{abstract}

Keywords: Pre-service teachers, Competence, Professional standards.

\section{INTRODUCTION}

The "Professional Standards for Primary School Teachers (Trial)" clearly states that primary school teachers should have three basic contents: professional concepts and teacher ethics, professional knowledge and professional capabilities. In the Ministry of Education's "Opinions on the Implementation of the Excellent Teacher Training Program", it is clearly pointed out that "to cultivate a large number of outstanding primary school teachers who love elementary school education, and whose teachers have extensive knowledge and high quality can be competent for the multi-disciplinary integration of primary schools." David McClelland proposed that competency is a personal characteristic that distinguishes outstanding achievers from ordinary people at work, including motivation, traits, attitudes or values, knowledge, skills, etc. Xu Jianping's research found that the competency structure of excellent teachers includes initiative [1-3], sense of responsibility, understanding of others, self-control, professional knowledge and skills, emotional awareness, challenge and support, self-confidence, conceptual thinking, self-evaluation, and sense of efficiency; those of ordinary teachers Competency structure includes organization and management ability, integrity and honesty, creativity, tolerance, teamwork, reflective ability, career preferences, communication skills, respect for others, analytical thinking, and stable emotions. Whether pre-service teachers have the ability to be a competent teacher is particularly important. It is of great value to study the professional standards of primary school pre-service teachers from the perspective of competence.

The research on the professional standards of pre-service teachers in western elementary schools can continuously optimize the construction of the teaching team, lead the professional development of pre-service teachers in primary schools, and promote the internal transformation of pre-service teachers from professional unawareness to their own professional growth. It is conducive to promoting the quality of basic education in the western region [4-5], promoting education fairness, accelerating the modernization of education, building an education power, and running education that satisfies the people. The research comprehensively uses the literature method, BEI and questionnaire method to 
construct and verify the competency model of pre-service teachers in western elementary schools. Focus on the framework and content of the professional standards for pre-service teachers in elementary schools, and further understand the basic status and improvement measures of the pre-service teachers' professional levels in western elementary schools through research.

\section{CONSTRUCTION OF COMPETENCY MODEL OF PRE-SERVICE TEACHERS IN WESTERN PRIMARY SCHOOLS}

\subsection{Compilation of the competency dictionary of pre-service teachers in western elementary schools}

Adopt open-ended questions to invite education department leaders related to primary school pre-service teacher positions, college primary school education teachers, primary school pre-service teachers, primary school students, college primary school education majors, and primary school students' parents to participate in the collection of entries. The title is "General Primary School Jobs" 10-15 entries for the competence of former teachers", compile the "Western Primary School Pre-service Teacher Competency Dictionary" based on the elements of the general competency dictionary [6-8]. The dictionary entries have been sorted out, including interpersonal understanding, achievement orientation, initiative, information collection, relationship building, self-control, self-confidence, responsibility, cultivating others, teamwork, caring for others, awareness, innovation ability, learning development, and self-discipline , Organizational identification, integrity, flexibility and adaptability, openness of experience, empathy, analysis and judgment, charisma, attention to detail, execution, guidance and monitoring, knowledge and skills.

\subsection{Construction of competency model for pre-service teachers in western elementary schools}

Use behavioral incident interview method to collect materials, with topics including "tell the 3 most successful incident cases at work, the more detailed the content, the better, focusing on how you dealt with the incident" "tell the 3 most failed incident cases at work", Focusing on how you handled the incident." The interviewees were mainly pre-employment teachers in elementary schools in the western region who were about to join the job. A total of 41 specific incident materials were obtained.

Organize the team members to code the competency characteristics. Three people with the highest consistency in precoding were selected to form a coding team, and 41 event cases were coded. The indicators were mainly the average grade scores of competency characteristics, and SPSS20.0 software was used for data statistics. The results are as follows:

Table 1. Statistics of average grade scores of competency characteristics

\begin{tabular}{|c|c|c|c|c|c|c|c|c|c|c|c|}
\hline $\begin{array}{l}\text { Interpersonal } \\
\text { understanding }\end{array}$ & & & & & & & & & & & \\
\hline Achievement-oriented & 0.020 & & & & & & & & & & \\
\hline Initiative & 0.013 & 0.006 & & & & & & & & & \\
\hline Sense of responsibility & 0.022 & 0.014 & 0.013 & & & & & & & & \\
\hline Self-confidence & 0.024 & 0.055 & 0.010 & 0.041 & & & & & & & \\
\hline Nurture others & 0.015 & 0.000 & 0.000 & 0.000 & 0.010 & & & & & & \\
\hline teamwork & 0.001 & 0.011 & 0.000 & 0.000 & 0.014 & 0.002 & & & & & \\
\hline Creativity & 0.050 & 0.031 & 0.041 & 0.042 & 0.030 & 0.573 & 0.040 & & & & \\
\hline concern for others & 0.045 & 0.067 & 0.040 & 0.337 & 0.501 & 0.120 & 0.131 & 0.016 & & & \\
\hline Awareness & 0.035 & 0.007 & 0.010 & 0.104 & 0.158 & 0.121 & 0.144 & 0.657 & 0.030 & & \\
\hline Learning development & 0.016 & 0.047 & 0.031 & 0.064 & 0.057 & 0.228 & 0.234 & 0.145 & 0.178 & 0.037 & \\
\hline Knowledge and skills & 0.000 & 0.000 & 0.008 & 0.000 & 0.000 & 0.004 & 0.000 & 0.002 & 0.000 & 0.000 & 0.000 \\
\hline
\end{tabular}

**. Significantly correlated at the .01 level (two-sided).

From the average score index of the statistical table, the analysis indicators of the competency model for pre-service teachers in western elementary schools include interpersonal understanding, achievement orientation, initiative, sense of responsibility, self-confidence, cultivating others, teamwork, innovation ability, caring for others, Perception, learning development, knowledge and skills. From the analysis of statistical results, the relationship between indicators is statistically significant at the $p<0.05$ level. Indicators include knowledge and skills, teamwork, achievement orientation, initiative, responsibility, cultivating others, and interpersonal understanding.
Reliability analysis uses the coder to explain the percentage of the same text material classified as a percentage of the total number of codes. The result is $88.0 \%$, which meets the reliability requirements. Validity analysis adopts surface validity index, and randomly invites western elementary school pre-service teachers to analyze the model's knowledge and skills, teamwork, achievement orientation, initiative, sense of responsibility, cultivating others, interpersonal understanding and other indicators, and the feedback consistency reaches $95 \%$, which meets the validity requirements. 


\subsection{Verification of the competency model of pre-service teachers in western elementary schools}

\subsubsection{Research process}

According to the competency index structure of pre-service teachers in western elementary schools, following the questionnaire preparation process, through pre-testing, collation, project analysis and reliability and validity analysis, the formally implemented "Western Primary School Pre-service Teacher Competency Model Verification Questionnaire" was revised. Using questionnaires, a random sampling survey was conducted among pre-service teachers in primary schools in Inner Mongolia, Xinjiang, Tibet, Chongqing and Yunnan. A total of 1018 questionnaires were collected. After sorting out, 80 invalid questionnaires and 938 valid questionnaires were eliminated. The use rate of questionnaires was $92.14 \%$. The data adopts SPSS20.0 statistical processing.

\subsubsection{Results and analysis}

\subsubsection{Exploratory factor analysis of the competency structure of pre-service teachers in western elementary schools}

Bartlett's sphere test and $\mathrm{KMO}$ value analysis were performed on the data. The KMO value was 0.912 (close to 1), which is suitable for factor analysis. The results of factor analysis, total variation explanation rate, factor characteristic values and contribution rates are shown in Table 2.

Table 2. Factor analysis results and index total variation interpretation rate

\begin{tabular}{llll}
\hline Factor & Characteristic value & Percentage of variation (\%) & Cumulative percentage of variation (\%) \\
\hline 1 & 7.411 & 23.015 & 23.015 \\
2 & 4.146 & 13.977 & 36.992 \\
3 & 2.401 & 7.442 & 44.414 \\
4 & 2.036 & 6.323 & 50.737 \\
5 & 1.823 & 5.511 & 56.248 \\
6 & 1.554 & 4.993 & 61.241 \\
7 & 1.474 & 4.806 & 66.047 \\
\hline
\end{tabular}

After exploratory factor analysis, it is found that when the cumulative rate of variation stabilizes, the 7-dimensional pre-service teacher competency index structure of western elementary schools is obtained, and the cumulative variance explanation rate is $66.047 \%$. Therefore, seven indicators can be used to explain the competency index structure of pre-service teachers in western elementary schools. They are named: knowledge and skills, teamwork, achievement orientation, initiative, responsibility, cultivating others, and interpersonal understanding.

\subsubsection{Analysis of reliability and validity of competency structure of pre-service teachers in western elementary schools}

Carry out further Pearson correlation significance (bilateral) analysis on the data, in-depth understanding of the consistency and stability of the competency structure of pre-service teachers in western elementary schools, and conduct reliability and validity analysis. The results are shown in Table 3 .

Table 3. Pearson correlation analysis among various factors

\begin{tabular}{|c|c|c|c|c|c|c|c|}
\hline Knowledge and skills & 1.000 & & & & & & \\
\hline Teamwork & $.592^{88}$ & 1.000 & & & & & \\
\hline Achievement-oriented & $.602^{* *}$ & $.692^{* 8}$ & 1.000 & & & & \\
\hline Initiative & $.547^{* 8}$ & $.556^{88}$ & $.690^{88}$ & 1.000 & & & \\
\hline Sense of responsibility & $.518^{* *}$ & $.588^{* 8}$ & $.543^{8 *}$ & $.687^{* 8}$ & 1.000 & & \\
\hline Nurture others & $.551^{* 8}$ & $.557^{* 8}$ & $.624^{8 *}$ & $.638^{88}$ & $.765^{* 8}$ & 1.000 & \\
\hline Interpersonal understanding & $.536^{* *}$ & $.714^{* 8}$ & $.611^{8 *}$ & $.620^{* *}$ & $.613^{* 8}$ & $.634^{* 8}$ & 1.000 \\
\hline
\end{tabular}

**. Significantly correlated at the .01 level (two-sided).

According to the analysis, it is found that the correlation coefficient between the competency structure factors of pre-service teachers in western elementary schools is between 0.518-0.714, which is at a medium degree of correlation, and is significantly correlated at the level of 0.01 , indicating that each factor can contribute to the total competency score. The validity is acceptable.

\subsubsection{Verification analysis of competency structure of pre-service teachers in western elementary schools}

Using Amos7.0 software to conduct a confirmatory analysis of the competency structure of pre-service teachers in western elementary schools, the results of factor fitting are shown in Table 4. 
Table 4. The fitting index statistics of the measurement model to the sample

\begin{tabular}{lcccccc}
\hline$x^{2}$ & df & $x^{2 / \mathrm{df}}$ & RMSEA & CFI & NFI & TLI \\
\hline 1158 & 495 & 3.211 & 0.054 & 0.915 & 0.932 & 0.927 \\
\hline
\end{tabular}

From the analysis data, it can be seen that the fitting index $\chi 2 / \mathrm{df}=3.211$ is between 2.0 and 5.0, RMSEA $=0.054$ is lower than 0.08 , and the CFI, NFI, and TLI values are all greater than 0.9 , indicating the degree of fit of the competency structure of pre-service teachers in western elementary schools Better, the model has a higher degree of fit and stability from the fitting index.

\section{A STUDY ON THE PROFESSIONAL STANDARDS OF PRE-SERVICE TEACHERS IN MIDDLE AND WESTERN PRIMARY SCHOOLS IN THE HORIZON OF COMPETENCY}

On the basis of the competency structure of pre-service teachers in western elementary schools and the "Professional Standards for Primary School Teachers (Trial)", explore the professional standards of pre-service teachers in western elementary schools.

\subsection{Knowledge and skills}

Pre-service teachers in western elementary schools must have a solid foundation of knowledge and skills, continuously optimize the knowledge structure system, and improve cultural literacy. Professional knowledge and skills cover the laws, regulations and policies of primary education, the laws of student growth and development, the laws of education and teaching, subject expertise, general knowledge, primary school student service management and management capabilities, and the ability to use new media to carry out teaching. Knowledge and skills are inherently consistent with the professional knowledge and professional abilities in the "Professional Standards for Primary School Teachers (Trial)".

\subsection{Teamwork}

The growth and development of pre-service teachers in western elementary schools is a progressive process, which is inseparable from the support and cooperation of leaders, colleagues, and even students. Pre-service teachers need to be able to actively integrate into the team, establish a scientific concept of cooperation and win-win, take the initiative in the team, dare to expose shortcomings and shortcomings, humbly listen to the opinions and suggestions of team members, and effectively promote their own growth. Teamwork is mainly embodied in the "Professional Standards for Primary School Teachers (Trial)". The professional philosophy and ethics of teachers have teamwork spirit, and actively carry out collaboration and exchanges.

\subsection{Achievement Oriented}

The achievement orientation of pre-service teachers in western elementary schools is embodied in their advanced and scientific professional concepts, their incomparable love for basic education and teaching, and their loyalty to the education profession. Be proactive in education, pay attention to professional development, establish the concept of lifelong learning, learn to self-regulate, and ensure that you have a positive motivation and attitude. Achievement orientation is closely related to the professional philosophy of the "Professional Standards for Primary School Teachers (Trial)", teacher ethics and professional ability.

\subsection{Initiative}

The particularity of teacher occupation determines that pre-service teachers in western elementary schools need to have more initiative. The physical and mental development of pupils has not reached the mature stage, and education service management requires teachers to make more efforts. On the one hand, teachers need to prepare enough homework, fully understand the physical and mental characteristics of primary school students, and master a variety of skills to motivate primary school students. On the other hand, it is necessary to give full play to the initiative in the process of education, teaching and service management, actively understand and discover the growth and changes of primary school students, maximize strengths and avoid weaknesses, take the initiative to reflect in educational and teaching practice activities, and strengthen research-based teaching. Initiative is important to the professional knowledge and professional ability of "Professional Standards for Primary School Teachers (Trial)".

\subsection{Responsibility}

A teacher is a profession of conscience. It requires primary school pre-service teachers to have a high sense of responsibility, adhere to the goal of cultivating people, be compassionate and warm to students, be patient and courageous in dealing with difficulties, and be careful and contribute to work. Responsibility and the professional philosophy of "Professional Standards for Primary School Teachers (Trial)" are consistent with the love, responsibility, patience and care of teachers' ethics. 


\subsection{Cultivate others}

Cultivating others is mainly for elementary school pre-service teachers to cultivate pupils' ideological awareness and realistic behavior, which is manifested by paying attention to the physical and mental development of pupils, actively paying attention to the changes of pupils, respecting pupils, guiding pupils to develop good living and learning habits, and allowing pupils to grow as much as possible. . Give affirmative evaluation to the development of students, and adopt a variety of methods to promote positive changes in students. Cultivating others and the professional concept of "Professional Standards for Primary School Teachers (Trial)" are connected with teachers' ethics and professional ability.

\subsection{Interpersonal understanding}

Interpersonal understanding is manifested in the establishment of interpersonal relationships and interpersonal communication. Primary school pre-service teachers need to be able to establish good interpersonal relationships with teachers, students, parents, etc., and be good at actively listening to multiple suggestions to improve their work. At the same time, master the necessary communication skills in the process of interpersonal communication, and be able to accurately and effectively capture the core information of the other party, cooperate and communicate with the other party, share experience, and give timely feedback to improve the quality of communication. Interpersonal understanding is related to the professional ability of "Professional Standards for Primary School Teachers (Trial)".

Table 5. Statistical analysis of demographic variables
The professional standards for pre-service teachers in western elementary schools are highly related to the dimensions, fields and requirements of the "Professional Standards for Primary School Teachers (Trial)". Many indicators overlap with the content of the "Professional Standards for Primary School Teachers (Trial)", and fully emphasize the concept of teacher ethics, Student-oriented, ability-oriented and lifelong learning requirements. This standard can provide an important reference for the training of elementary school teachers, as well as for the reform of the training of teachers for elementary education majors.

\section{INVESTIGATION AND RESEARCH ON THE STATUS QUO OF PRE-SERVICE TEACHERS' PROFESSIONAL ABILITY IN WESTERN PRIMARY SCHOOLS}

\subsection{Analysis of survey respondents}

According to the process of questionnaire preparation, analysis, pre-test, revision, etc., a self-compiled questionnaire "Questionnaire on the Professional Ability Status of Western Primary School Teachers" was used to conduct a sample survey among primary school pre-service teachers in Inner Mongolia, Xinjiang, Tibet, Chongqing and Yunnan. This assesses the professional level of pre-service teachers in western elementary schools. A total of 1258 questionnaires were collected. After sorting out, 131 invalid questionnaires and 1127 valid questionnaires were eliminated. The use rate of questionnaires was $89.59 \%$. The data adopts SPSS20.0 statistical processing. The statistical analysis of the demographic variables of the survey subjects is as follows:

\begin{tabular}{|c|c|c|c|}
\hline \multicolumn{2}{|l|}{ Basic information } & Frequency & percentage $(\%)$ \\
\hline \multirow{2}{*}{ gender } & male & 472 & 41.9 \\
\hline & Female & 655 & 58.1 \\
\hline \multirow{3}{*}{ Education } & Specialist and below & 262 & 23.2 \\
\hline & Undergraduate & 797 & 70.8 \\
\hline & Postgraduate and above & 68 & 6.0 \\
\hline \multirow{2}{*}{ Whether to pass the teacher qualification examination } & Yes & 997 & 88.5 \\
\hline & no & 130 & 11.5 \\
\hline
\end{tabular}

From the sample data, the proportion of females is $58.1 \%$, which is roughly the same as the current gender ratio structure of primary education students. The proportion of female students studying primary education is high. The degree of education is mainly undergraduate, reaching $70.8 \%$. The survey sample is mainly in the western region. At present, the qualification threshold for employment in primary education is relatively low, which can be satisfied by undergraduate. In remote areas, in order to meet the needs of the construction of the teaching staff, specialist courses also meet the recruitment requirements. From the perspective of whether or not they passed the teacher qualification examination, $11.5 \%$ of the subjects failed. Due to the changes in the application for teacher qualification in recent years, they all need to pass the examination certification. A certain proportion of students are prone to problems in the certification process, resulting in Cannot successfully obtain the teacher qualification certificate. 


\subsection{Analysis of the Professional Ability of Pre-service Teachers in Western Primary Schools}

Descriptive statistical analysis of various indicators of pre-service teachers' professional

Table 6. Statistical Analysis of the Professional Ability of Pre-service Teachers in Western Primary Schools

\begin{tabular}{lrrrr}
\hline \multicolumn{1}{c}{ index } & Sample & maximum & mean & standard deviation \\
\hline Knowledge and skills & 1127 & 12.00 & 6.984 & 2.027 \\
teamwork & 1127 & 12.00 & 6.800 & 1.925 \\
Achievement-oriented & 1127 & 15.00 & 8.460 & 2.107 \\
Initiative & 1127 & 12.00 & 7.457 & 2.017 \\
Sense of responsibility & 1127 & 15.00 & 8.855 & 1.987 \\
Nurture others & 1127 & 27.00 & 7.110 & 1.926 \\
Interpersonal understanding & 1127 & 15.00 & 8.681 & 2.094 \\
\hline
\end{tabular}

According to the analysis of sample results, the knowledge and skill index of pre-service teachers in western elementary schools is $6.894 \pm 2.027$, the highest score is 12.00 ; the teamwork is $6.800 \pm 1.925$, the highest score is 12.00; the achievement orientation is $8.460 \pm 2.107$, the highest score 15.00 ; initiative is $7.457 \pm 2.017$, the highest score is 12.00 ; the sense of responsibility is $8.855 \pm 1.987$, the highest score is 15.00 ; the cultivation of others is $7.110 \pm 1.926$, the highest score is 27.00; the interpersonal understanding is $8.681 \pm 2.094$, the highest score is 15.00 . On the whole, the overall situation of pre-service teachers' professional competence in western elementary schools is good. The main reason is that the primary school education teacher major is highly valued, and more opportunities for improvement have been obtained in the education reform and teacher professional certification. Characterized and professional elementary education professionals the training effect is more prominent. From the previous focus on the knowledge and skills requirements of primary school pre-service teachers, gradually shifting to focus on the training of their professional abilities and professional qualities at the same time, the comprehensive literacy of primary school pre-service teachers has improved significantly. The relatively weak ability of cultivating others in the indicators of pre-service teacher professional ability in western elementary schools may be due to the fact that the students have not formally entered the teacher position, and the training of knowledge and skills is a larger proportion, and the habit formation and practice of primary school students have not been paid attention to. Ability, interpersonal communication skills and other all aspects of training. competence in western elementary schools, the results are as follows.

\section{AN ANALYSIS OF THE WAYS TO IMPROVE THE PROFESSIONAL ABILITY OF PRE-SERVICE TEACHERS IN WESTERN PRIMARY SCHOOLS}

\subsection{Strengthen the reform of professional talent training and focus on the comprehensive literacy of pre-service teachers}

Continuously improve the reform of the primary education professional talent training program, further clarify and revise the primary education professional talent training objectives, content, curriculum system, reform strategy, system improvement and talent training evaluation and other elements, and strengthen the combination and optimization of the talent training program. The reform of the talent training program is based on the "Professional Standards for Primary School Teachers (Trial)", and fully considers the core qualities of pre-service teachers in the primary education major, focusing on the psychological characteristics, professional concepts, education and teaching reflected in the pre-service teachers' moral qualities. Comprehensive cultivation of knowledge and skills, comprehensive literacy and growth and development. Continue to study and explore ways to reform and practice pre-service teacher training, condense experience and characteristics for promotion, and better promote the cultivation of pre-service teachers in primary education.

\subsection{Strengthen the professional practice of primary school education and improve the practical ability of pre-service teachers}

Based on the training goals and requirements of pre-service teachers in primary schools, construct a practice-oriented, diversified, integrated practice curriculum system that integrates pre-service and post-service. Emphasizing ability first, highlighting the core position of practical courses, ensuring the deep 
integration and extension of practical courses and theoretical courses, through cross-participation in educational practice and educational situational experience, allowing students to internalize and practice theoretical learning and accumulate experience in practice. Develop skills in practice and feed back theoretical reflections in practical courses through practice. Based on the study of theoretical courses, through practice, internships, research, lectures, and simulations, the theory and practical situations are effectively combined, the "inter-embedded" professional training is implemented, and the theory-practice-theory alternate cycle is established. Development model. At the same time, adopt a developmental practical curriculum evaluation method to evaluate the practical curriculum of primary school pre-service teachers, strengthen supervision and feedback on teaching design, trial lectures and internship reports, and effectively promote primary school education pre-service teachers Self-discipline and development.

\subsection{Attach importance to the cultivation of pre-service teachers' ethics and improve the guarantee conditions for talent cultivation}

Relying on the professional curriculum of primary school education, integrating into the construction and teaching of teacher ethics curriculum, strengthening the construction of teacher ethics and teaching style, promoting pre-service teachers to establish the awareness and concept of educating themselves now and in the future, and fostering a sense of social responsibility and mission of the teacher profession. In the process of cultivating teacher ethics, guide pre-service teachers to realize the positive effects of teacher ethics on personal development and accomplishment, abide by the basic principles of teacher professional ethics, establish a correct outlook on the world, life, values, and justice, and have lofty ideals and beliefs, Has a tenacious will and lofty ideological realm. Pay attention to the improvement of the theory of teacher ethics and the practical ability of teacher ethics, consciously cultivate the sentiment of teacher ethics, so as to "educate people first, educate yourself, and educate yourself first." In the cultivation of practical ability, the introduction of excellent teacher ethics cases and role models to educate and influence pre-service teachers, let them experience the noble teacher ethics and personality charm, and subtly cultivate their excellent qualities. In the process of teacher ethics training, establish and improve the teacher ethics evaluation mechanism for pre-service teachers, and incorporate the evaluation of teacher ethics into the design of the talent training program.

In addition, continue to deepen the reform of primary school education professional evaluation and certification, set up teacher education courses scientifically, and reform education and teaching methods; establish a pre-service teacher talent quality assurance system to continuously improve the quality of primary school teacher training; pay attention to the professional ethics education of primary school teachers, and value social practice and Educational practice; focus on teachers' professional ideals and professional ethics education, strengthen teachers' sense of responsibility and mission in educating people; rationally guide pre-service teachers to carry out self-professional development planning, love their jobs and work, enhance professional development consciousness, and gradually improve professional development.

\section{CONCLUSIONS}

The competence structure of pre-service teachers in western elementary schools includes knowledge and skills, teamwork, achievement orientation, initiative, responsibility, cultivating others and interpersonal understanding. These elements are consistent with the professional philosophy and professional ethics, professional knowledge and professionalism of elementary school teachers' professional standards. Contents such as ability are very consistent. The empirical investigation found that the competence levels of pre-service teachers in western elementary schools are not uniform, and proposed reforms to strengthen the training of professional talents, focusing on the comprehensive literacy of pre-service teachers; strengthening the professional practice of primary school education and improving the practical ability of pre-service teachers; attaching importance to the cultivation of pre-service teachers' ethics, improving the guarantee conditions for talent training and other suggestions, hoping to provide meagre power for the training and self-improvement of primary school teachers.

\section{ACKNOWLEDGMENTS}

About the author: Li Guang (1984-), male, from Xuanwei, Yunnan, associate professor of Baoshan College, master degree, mainly engaged in human resource management psychology, teacher education, mental health education research; mailing address: Longyang District, Baoshan City, Yunnan Province Road 16.

Funding project: Baoshan College Social Science Research Project "Research on the Professional Standards of Pre-service Teachers in Western Primary Schools from the Perspective of Competency" (No. BYPY202009) Phase Achievement; Yunnan Provincial Education Department Scientific Research Fund Project "Primary School Teachers' Competency from the Perspective of Professional Standards" Research" (No. 2020J0692) was funded. 


\section{REFERENCES}

[1] Spencer L. M, Spencer S. M. Competence at Work Models for Superior Performance [M]. New York: John Wiley \& Sons, Inc.1993.86.

[2] Richard E Boyatzes. The Comepent Manager: A model for effective performance [M]. Canada: John Wiley\& Sons Inc, 1982.

[3] Mc Clelland, C.David. Testing for Competence Rather Than for Intelligence [J]. American Psychologist, 1973, 28(1):1-4.

[4] Yin Zhihua, Wang Xiaozan, Sun Mingzhu, Phillip Ward. "A weapon" or a "chicken rib"__ The effect of professional standard certification for pre-service physical education teachers in the United States and the warning to my country's professional certification $[\mathrm{J}]$. Journal of Wuhan Institute of Physical Education, 2021, 55(08):79-86.

[5] Yin Zhihua, Wang Xiaozan, Qin Li. Canadian pre-service physical education teachers' professional standards and their application research [J]. Journal of Xi'an Institute of Physical Education, 2021, 38(03): 277-285.

[6] Wu Xinchun. Child Development and Educational Psychology [M]. Beijing: Higher Education Press, 2013.

[7] Wang Yu. Research on the Evaluation of Teaching Performance of Pre-service Teachers in Australia [D]. Northeast Normal University, 2020.

[8] Li Guang, Li Kaimin. Competency model testing from the perspective of college counselors' professional competence standards $[\mathrm{J}]$. Journal of Baoshan University, 2017, 36(04): 19-25+68. 